\title{
ASSESSMENT OF THE PERFORMANCE OF NOVICE FUTSAL PLAYERS IN THE EXECUTION OF FUTSAL-SPECIFIC MOTOR SKILLS
}

original paper

(1) University School of Physical Education in Wroclaw

DOI: https://doi.org/10.5114/hm.2019.83994

\section{MARCOS REIS ${ }^{1,2}$, JENISSON SANTOS ${ }^{1}$, MATHEUS MATOS ${ }^{1}$, THAYRON CRUZ ${ }^{1}$, FABRICIO VASCONCELLOS ${ }^{3}$, MARCOS ALMEIDA ${ }^{2}$}

${ }^{1}$ Group of Study and Research in Team Sports, Department of Physical Education, Estácio College of Sergipe, Aracaju, Brazil

${ }^{2}$ Laboratory of Study and Research in Performance in Exercise and Sport, Postgraduate Program in Physical Education, Federal University of Sergipe, São Cristóvão, Brazil

${ }^{3}$ Laboratory of Soccer Studies, Postgraduate Program in Exercise and Sport Sciences, State University of Rio de Janeiro, Rio de Janeiro, Brazil

\begin{abstract}
Purpose. To compare the performance in the execution of specific motor skills among novice futsal players in 3 competitive categories (U-7, U-9, and U-11) and to compare their performance in specific motor skills during the offensive and defensive phases of the game.

Methods. Ten specific motor skills were investigated, including 6 offensive actions and 4 defensive actions, in 49 futsal players aged 6-11 years. Technical performance was analysed in terms of the number of actions, the effectiveness of the action (successful or unsuccessful), and where the action occurred (offensive or defensive midfield). One-way ANOVA was used with the Tukey test, when appropriate, or Student's t-test, with a significance level of 5\%.

Results. Players in the older categories were more effective defensively than those in the younger categories $\left(F_{2,46}=6.04\right.$, $p<0.01$, partial $\eta^{2}=0.21$ ). The two older groups had an approximately two- and three-fold greater chance, respectively, of executing successful defensive technical actions $(O R=1.82, p<0.05 ; O R=2.83, p<0.01)$. Furthermore, the players were more technically effective in the offensive phase of the game than in the defensive phase $(M=41.35, S D=21.53$ and $M=16.47$, $S D=7.90$, respectively; $t_{96}=7.60, p<0.01, d=1.69$ ).
\end{abstract}

Conclusions. Players in older competitive categories were more effective, and players were more effective offensively than defensively.

Key words: motor learning, children, team sports, technical assessment

\section{Introduction}

Futsal-specific motor skills can be defined as technical actions primarily carried out through ball possession (offensive actions) or when a player attempts to recover ball possession directly of an adversary with a ball (defensive actions) [1, 2]. Thus, the execution of technical actions aims to operationalize the mental decision-making of players through a motor action, solving the specific problems of each game phase with maximum energy economy [3, 4].

In this way, technical performance may be identified by the quantity and effectiveness of offensive and defensive actions, as well as the location on the playing field where actions occur [3]. Technical performance must be analysed in a game-like perspective because it is associated with the tactical behaviour, and together they form the futsal players' processual knowledge $[4,5]$. They encompass 'the reason to make' (tactical behaviour) and 'how to make' (technical performance) an action [5].

Futsal game is a donor sport to soccer game because many players learned motor skills of soccer when playing futsal in sport initiation [6]. In this sense, futsal players aged 12-17 years exhibit better tactical performance than soccer players; they make less frequent

Correspondence address: Marcos Reis, Group of Study and Research in Team Sports, Department of Physical Education, Estácio College of Sergipe, Street Teixeira de Freitas, Salgado Filho, Aracaju - SE, Brazil, e-mail: mamreis91@gmail.com

Received: November 9, 2018

Accepted for publication: December 10, 2018

Citation: Reis M, Santos J, Matos M, Cruz T, Vasconcellos F, Almeida M. Assessment of the performance of novice futsal players in the execution of futsal-specific motor skills. Hum Mov. 2019;20(3):29-37; doi: https://doi.org/10.5114/hm.2019.83994. 
errors in executing fundamental tactical principles [7]. In futsal, players (mean age: 13 years) who only practiced this sport performed more successful passes in soccer games and they had less time in ball-focused attention than soccer players [8]. More passes, smaller individual play area and ball reception time produce the futsal game more technically intense than soccer [9].

Furthermore, deliberate practice influences the development of futsal players' technical performance. Futsal players aged 12-15 years who were classified as experienced (5 or more years of practice) were more effective in ball possession, kicking, and dribbling than were their less experienced peers [10]. Likewise, elite U-17 players have more contact time with the ball when kicking than non-elite players [11].

However, prior studies have focused on evaluating adolescent futsal players over the course of sports development, i.e., between 12 and 17 years of age [12, 13]. Thus, scientific studies are ignoring how players perform specific motor skills between 6 and 11 years, a crucial moment of motor learning phase $[14,15]$, besides focusing only on the execution of offensive actions, neglecting the defensive results of the players.

Beyond performance assessment through different ages between 6 and 11 years, futsal players can perform different pattern actions of offensive and defensive phases of the game. For example, in professional futsal, the execution of defensive variables brings positive results to teams [16]. On the other hand, spatial references are also influential factors in the players' performance and it is needed to take them into account in the assessment process of futsal performance [17].

To the best of our knowledge, there are no scientific reports concerning specific motor skill performance in novice futsal players (6-11 years) with little time of deliberate practice (less that 1 year). In addition, there is a gap in the assessment of specific motor skills, as prior research has disregarded defensive aspects [18] or ecological situations (many times, technical actions are evaluated in situations out of game, e.g. dribbling between targets, without opposition) [19, 20].

This information obtained through technical assessment from a comprehensive ecological perspective may be relevant to the motor learning process because most elite futsal players start the sport at the age of 6-10 years [21]. Therefore, understanding how age influences, in this phase of life (6-11 years), the specific motor skills of novice futsal players is an important factor in the sports training process.

Thus, the objective of the study was two-fold: to compare the performance in the execution of specific motor skills among novice futsal players in 3 competitive cate- gories (U-7, U-9, and U-11) and to compare their performance in specific motor skills during the offensive and defensive phases of the game.

\section{Material and methods}

\section{Participants}

Overall, 49 line futsal players with a mean $(M)$ age of 8.61 years and standard deviation $(S D)$ of 1.52 years (16 in the U-7 category, with $M=6.74, S D=0.53$ years of age; 19 in the U-9 category, with $M=9.04, S D=0.31$ years of age; and 14 in the U-11 category, with $M=10.22$, $S D=0.43$ years of age) participated in the study. The subjects were enrolled in a futsal school for sports training purposes and were evaluated during a friendly championship in which they competed only against teams in the same competitive category. The participants had less than a year of experience, and the training programme consisted of 2 weekly sessions lasting not more than 1 hour each.

\section{Instrument}

Specific motor skills were ecologically assessed through analyses of videotaped games [22]. A digital camera (Sony W830 20.1 megapixel HD, Japan) and a professional tripod (Sl-2111, 1.20 meters) were applied to record the games for further analysis. A notebook (Samsung Expert VD1BR Intel Core I5 8GB Geforce MX110 with 2GB 1TB LED HD 15.6” W10) was used to analyse the videotaped games with Windows Movie Maker software. All data collected were placed in a specific Microsoft Excel spreadsheet developed for the purpose.

\section{Procedures}

For each category, a lottery system was used to allocate the subjects to teams. Futsal players were divided into teams GK +4 vs. $4+$ GK, and only line players were evaluated (goalkeepers were not). All games occurred on a $26 \times 15 \mathrm{~m}$ court and lasted 20 minutes. Only 1 game per player was evaluated, except when in the U-9 and and U- 11 categories 5 and 2 players performed 2 games to complete the last game, respectively. The games took place on different days. All futsal rules were preserved (Figure 1).

Ten specific motor skills were identified, including 6 offensive and 4 defensive actions. Offensive actions were considered exclusively for the player with direct control of the ball, while defensive actions were inves- 


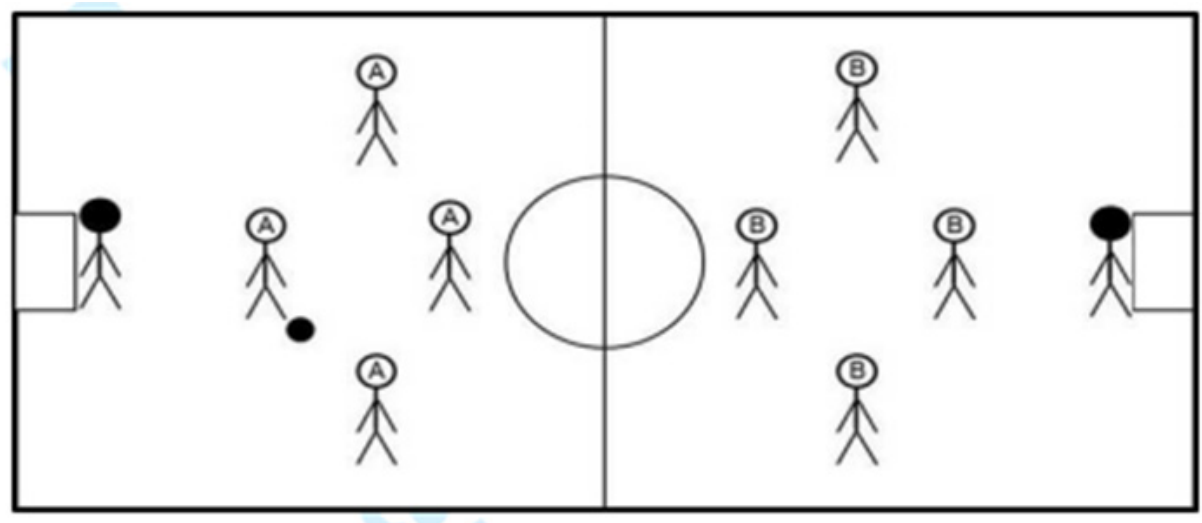

Figure 1. Structural organization of the technical evaluation protocol. Image based on the study of Reis, Vasconcellos, and Almeida [28]

Table 1. Conceptual definitions of the futsal-specific motor skills assessed in the study

\begin{tabular}{l} 
Specific motor skills - technical actions \\
\hline Offensive phase: offensive technical actions (player with the ball) \\
\hline Goal kick: kicking the ball to the opponent's goal \\
Pass: transmitting the ball to a player of the same team \\
Dribble: deceiving the opponent(s) in overdrive and in any direction \\
Ball handling: progressing with controlled ball possession in any direction on the court \\
Control / ball protection: gaining possession of a ball after a pass or a loose ball AND keeping control of the ball \\
Offensive heading: touching the ball with the head, either to finalize the goal or to pass the ball to a teammate \\
(player without the ball but in direct pursuit of its recovery) \\
Shot block: taking action to prevent the opponent from reaching the target \\
Interception: attempting to interrupt a pass made by opposing players or to gain possession of a loose ball AND keeping \\
control of the ball \\
Tackle: making direct contact with a player with the ball to recover it \\
Defensive header: touching the ball with the head to recover it
\end{tabular}

tigated for every player trying to recover the ball by directly facing the opponent controlling the ball or intercepting passes or loose balls. Specific motor skills (technical actions) were defined on the basis of a study by Guilherme et al. [1] (Table 1).

Technical performance was analysed in terms of the number of actions, the effectiveness of the action (successful or unsuccessful), and where the action occurred (offensive or defensive midfield) [3]. An action was considered successful in accordance with the following criteria: (a) for goal kicking and offensive heading, if the ball hit the goal or was touched by the goalkeeper and/or the opposing team's goalpost; and (b) for other technical actions, if the play generated maintenance of ball possession (for offensive actions) or ball recovery (for defensive actions) [1]. An action was considered maintenance or ball recovery in any of the following 3 cases: a successful pass immediately after an action, a sequence of 3 or more touches to the ball (by the same player), or a shot on goal [3].

\section{Statistical analyses}

Statistical analysis was performed with the SPSS 20.0 statistical software (IBM, USA), and a significance level of $5 \%$ was adopted; we thus report $95 \%$ confidence intervals $(95 \% \mathrm{CI})$. We first verified the normality of the data distribution using the Kolmogorov-Smirnov test $(p>0.05)$. The competitive categories were compared. For this purpose, a one-way analysis of variance (ANOVA) was applied, followed by the post-hoc Tukey tests when appropriate. Subsequently, the effect size relative to the comparison among 3 or more variables was assessed in terms of partial $\eta^{2}$ [23]. For the 
analysis of offensive vs. defensive technical performance, Student's $t$-test was used, and the effect size was assessed in terms of Cohen's $d$ [23, 24].

Comparisons were performed for the following variables: number of technical actions, number of technical offensive and defensive actions, offensive technical actions performed on the offensive field vs. defensive technical actions performed on the defensive field, percentage of successful technical actions, percentage of successful offensive and defensive technical actions, and percentage of successful offensive technical actions on the offensive field vs. percentage of successful defensive technical actions on the defensive field. We also estimated odds ratios (ORs) based on the percentage of successful technical actions, the percentage of successful offensive technical actions, and the percentage of successful defensive technical actions among the competitive categories across a $2 \times 2$ contingency table $(\mathrm{U}-7 \times \mathrm{U}-9$; U-7 $\times$ U-11; U-9 $\times$ U-11) [25].

The reliability of the data coding was tested with inter-rater and intra-rater concordance analyses based on a doubling analysis of ca. $10 \%$ of the total technical actions performed by the players. Technical actions were randomly selected for reanalysis 30 days after the first analysis. The concordance analysis was performed by using the kappa index and showed a high degree of reliability $(\mathrm{K}$ inter-rater index $=0.79$, $p<0.05$; K intra-rater $=0.77, p<0.05)[26]$.

\section{Ethical approval}

The research related to human use has complied with all the relevant national regulations and institutional policies, has followed the tenets of the Declaration of Helsinki and the National Health Advisory Board, and has been approved by the authors' institutional ethics committee.

\section{Informed consent}

Informed consent has been obtained from all individuals included in this study.

\section{Results}

The analysis comprised a total of 2833 technical actions that were stratified into 2026 offensive technical actions, 807 defensive technical actions, 920 offensive technical actions on the offensive field, and 490 defensive technical actions on the defensive field (Table 2).

There were no significant differences between the categories in the number of technical actions performed; however, older players (U-9 and U-11) performed technical actions and offensive technical ac- tions in greater quantity than younger players (U-7) (technical actions: $F_{2,46}=2.17, p=0.13$; offensive technical actions: $F_{2,46}=2.54, p=0.09$; defensive technical actions: $F_{2,46}=2.38, p=0.10$; Table 3). The U-9 players performed more defensive technical actions on the defensive field than the U-7 players did (offensive technical actions performed on the offensive playing field: $F_{2,46}=1.29, p=0.29$; defensive technical actions on the defensive playing field: $F_{2,46}=3.22$, $p=0.05$; Table 4).


Figure 2. (A) Mean and standard deviation of the percentage of successful technical actions (U-7 95\% CI: 52.98-71.19; U-9 95\% CI: 60.45-69.81; U-11 95\% CI: 66.13-75.87), offensive technical actions (U-7 95\% CI: 72.92-86.21; U-9 95\% CI: 70.48-78.01; U-11 95\% CI: 75.21-80.52), and defensive technical actions (U-7 95\% CI: 20.13-40.84; U-9 95\% CI: 38.76-51.81; U-11

95\% CI: 40.55-62.12); (B) percentage of successful offensive technical actions taken on the offensive field (U-7 95\% CI: 67.17-83.40; U-9 95\% CI: 64.95-75.06;

U-11 95\% CI: 68.40-81.76) and defensive technical actions on the defensive field (U-7 95\% CI: 15.73-45.69; U-9 95\% CI: 37.90-52.15; U-11 95\% CI: 37.49-66.12) by competitive category. (A) ${ }^{*} p<0.05$ in relation to $\mathrm{U}-7, * *$ $p<0.01$ in relation to $\mathrm{U}-7$. (B) \# $p<0.05$ in relation to $\mathrm{U}-11$. 
Table 2. Absolute counts of technical actions by competitive category

\begin{tabular}{lcccc}
\cline { 2 - 4 } & U-7 & U-9 & U-11 & Total \\
\hline Technical actions total & 753 & 1189 & 891 & 2833 \\
Offensive technical actions & 518 & 819 & 689 & 2026 \\
Defensive technical actions & 235 & 370 & 202 & 807 \\
Offensive technical actions on the offensive field & 267 & 413 & 240 & 920 \\
Defensive technical actions on the defensive field & 122 & 241 & 127 & 490 \\
\hline
\end{tabular}

Table 3. Means, standard deviations, and 95\% confidence intervals for total technical actions, total offensive technical actions, and total defensive technical actions by competitive category

\begin{tabular}{lccccc}
\hline Futsal-specific motor skills & $\mathrm{U}-7$ & $\mathrm{U}-9$ & $\mathrm{U}-11$ & $p$ & Partial $\eta^{2}$ \\
\hline Technical actions & $47.06 \pm 25.29$ & $62.58 \pm 24.07$ & $63.64 \pm 28.40$ & \multirow{2}{*}{0.13} & 0.09 \\
& $(33.40-60.35)$ & $(50.94-74.11)$ & $(47.61-80.39)$ & & \\
Offensive technical actions & $32.38 \pm 22.59$ & $43.11 \pm 16.85$ & $49.21 \pm 23.63$ & 0.09 & 0.10 \\
& $(20.34-44.41)$ & $(34.98-51.23)$ & $(35.57-62.86)$ & & \\
Defensive technical actions & $14.69 \pm 7.50$ & $19.47 \pm 8.40$ & $14.43 \pm 6.81$ & 0.10 & 0.09 \\
& $(10.69-18.68)$ & $(15.43-23.52)$ & $(10.49-18.36)$ & & \\
\hline
\end{tabular}

Table 4. Means, standard deviations, and 95\% confidence intervals for total offensive technical actions taken on the offensive field and total defensive technical actions performed on the defensive field by competitive category

\begin{tabular}{lccccc}
\cline { 2 - 5 } & $\mathrm{U}-7$ & $\mathrm{U}-9$ & $\mathrm{U}-11$ & $p$ & Partial $\eta^{2}$ \\
\hline Offensive actions on the offensive field & $16.69 \pm 12.59$ & $21.74 \pm 8.95$ & $17.14 \pm 9.03$ & 0.29 & 0.05 \\
& $(9.98-23.40)$ & $(17.42-26.05)$ & $(11.93-22.36)$ & & \\
Defensive actions on the defensive field & $7.63 \pm 5.19^{*}$ & $12.68 \pm 7.01$ & $9.07 \pm 5.68$ & $<0.05$ & 0.12 \\
& $(4.86-10.39)$ & $(9.31-16.06)$ & $(5.79-12.35)$ & & \\
\hline
\end{tabular}

${ }^{*} p<0.05$ in relation to U-9

No difference was found among groups in the percentage of successful offensive actions $\left(F_{2,46}=1.61\right.$, $p=0.21$, partial $\eta^{2}=0.07$ ) or offensive actions on the offensive field $\left(F_{2,46}=1.00, p=0.38\right.$, partial $\left.\eta^{2}=0.04\right)$. The players in the U-9 and U-11 categories were better at defensive technical actions compared with their U-7 counterparts $\left(F_{2,46}=6.04, p<0.01\right.$, partial $\left.\eta^{2}=0.21\right)$. The players in the U-11 category also performed more defensive technical actions on the defensive field than the U-7 players did $\left(F_{2,46}=3.44, p<0.05\right.$, partial $\eta^{2}=$ 0.13 ; Figure 2).

No significant differences were found between the U-9 and U-11 categories (percentage of successful technical actions: $O R=1.32,95 \%$ CI: 0.73-2.39, $p=$ 0.36 ; percentage of successful offensive technical actions: $O R=1.25,95 \%$ CI: 0.65-2.39, $p=0.51$; percentage of successful defensive technical actions: $O R=$ 1.27, 95\% CI: 0.73-2.22, $p=0.40$ ). The U-9 and U-11 players had (approximately) two- and three-fold greater odds of taking successful defensive technical actions, respectively, than the U-7 players (Table 5).
Table 5. Odds ratios (OR), 95\% confidence intervals (CI), and significance levels for successful technical actions, successful offensive technical actions, and successful defensive technical actions among competitive categories

\begin{tabular}{rrrr}
\cline { 2 - 3 } & OR & $95 \% \mathrm{CI}$ & $p$ \\
\hline
\end{tabular}

\begin{tabular}{|c|c|c|c|}
\hline \multicolumn{4}{|c|}{ Successful technical actions } \\
\hline U-9 & 1.14 & $0.64-2.03$ & 0.66 \\
\hline U-11 & 1.74 & $0.96-3.19$ & 0.07 \\
\hline
\end{tabular}

Successful offensive technical actions

$\mathrm{U}-7$

$\begin{array}{llll}\text { U-9 } & 0.71 & 0.37-1.38 & 0.31 \\ \text { U-11 } & 0.89 & 0.45-1.75 & 0.73\end{array}$

Successful defensive technical actions

$\mathrm{U}-7$

U-9 $\quad 1.82 \quad 1.02-3.25 \quad 0.04^{*}$

U-11 $2.83 \quad 1.59-5.06<0.01 *$

${ }^{*} p<0.05$ 
The players executed more offensive technical actions $(M=41.35, S D=21.53,95 \%$ CI: 35.16-47.53) than defensive technical ones $(M=16.47, S D=7.90$, 95\% CI: $14.20-18.74)\left(t_{96}=7.60, p<0.01, d=1.69,95 \%\right.$ CI: 1.08-1.98). They also performed a greater percentage of offensive technical actions $(M=77.02, S D=9.09$, 95\% CI: 74.41-79.63) than defensive technical actions $\left(M=42.18, S D=18.84,95 \%\right.$ CI: 36.77-47.59) $\left(t_{96}=\right.$ 11.66, $p<0.01, d=2.49$, 95\% CI: $1.82-2.85)$.

The players performed a greater number of offensive technical actions on the offensive field $(M=18.78$, $S D=10.36,95 \%$ CI: $15.80-21.75)$ than defensive technical actions on the defensive field $(M=10.00$, $S D=6.37,95 \%$ CI: 8.17-11.83) $\left(t_{96}=5.05, p<0.01\right.$, $d=1.04$, 95\% CI: 0.59-1.43). Similarly, the subjects had higher percentages of successful offensive technical actions on the offensive field $(M=73.18, S D=$ 12.51, 95\% CI: 69.59-76.77) than successful defensive technical actions on the defensive field $(M=42.29$, $S D=23.86,95 \%$ CI: 35.43-49.14) $\left(t_{96}=8.03, p<0.01\right.$, $d=1.69$, 95\% CI: $1.15-2.06)$.

\section{Discussion}

The main results of this study indicate that older players are more defensively effective than younger ones. Américo et al. [27] found a similar trend in an analysis of tactical aspects: the authors observed that U-17 and U-13 category players were more defensively effective than U-11 players. Such a finding can be explained by a natural learning process, in which players acquire skills as they age. The fact that this difference was found only in the defensive phase of the game can be justified by the overvaluation of offensive aspects in Brazilian culture [28].

Offensive skills are continuously highlighted over the years of playing development; thus, changes in offensive skills due to chronological ageing are not as noticeable as changes in defensive skills. This increase in defensive technical performance with chronological ageing may determine the future of the player because the defensive aspects of futsal can be a determinant of success for both professional futsal and soccer teams $[16,29,30]$.

It has also been found that players in the U-9 and U-11 categories are (approximately) two- and three-fold more likely, respectively, to perform successful defensive technical actions compared with U-7 players. This observation can be explained by natural cognitive maturation, which marks the onset of players' abstract thinking ability [31]. Consequently, in the present study, the players made better decisions regarding the execution of specific defensive motor skills. Thus, another important factor to discuss is the influence of biological maturation on the teaching and learning of techniques [11, 32]. The teacher/coach should be aware of the biological advantage that earlier-maturing players can acquire over their peers after the chronological age of 11 years to avoid promoting an unbalanced specialization process in the sport [33].

The current study also reported that the players as a whole were more effective offensively than defensively. These results corroborate (and complement) other studies that analysed the tactical aspects of soccer and futsal players aged 11-17 years [11, 27, 28, 34]. Moreover, it is very important to emphasize that the current study is the first to present data on futsal-specific motor skills in novice players.

It is essential that players have well-established offensive performance, but defensive skills are as crucial as offensive ones for a player's long-term development. In this way, the teaching-learning process in team sports should be based on holistic aspects that include didactic and pedagogical principles aiming to develop players' understanding of the game, ability to fulfil the demands of all phases of the game, and ability to solve problems during matches [35, 36]. This is principally because elite futsal players engaged in more sports practice time than did lower-level and amateur players [21], consequently obtaining more variability of stimuli and quality of sports practice [37].

This study offers an innovative approach for assessing futsal-specific motor skills in novice players from two perspectives. First, we analysed real game situations, respecting the ecological perspective inherent in sports practice, which allowed us to reliably investigate sports specialization. Second, we conducted a holistic assessment of players' technical performance based on a multitude of futsal-specific motor skills during both the offensive and defensive phases of the game. To the best of our knowledge, the scientific literature has not yet addressed these topics using such a comprehensive approach. Instead, previous research has investigated only isolated specific motor skills, e.g. kicking, dribbling, and ball control [10, 12, 13, 19].

We did not identify the zones, sectors, or corridors where technical actions were carried out, a fact that could be considered a limitation of the current study. Although a more detailed analysis could provide accurate information for performance assessment, the methods applied in the present investigation do not invalidate the relevance of the study, in which the 
playing field was studied in terms of two spatial references: the offensive and defensive midfield.

The practical implications of this research are to provide relevant information concerning training profiles during the introduction to futsal and contribute to sports training in terms of the technical skills of the game. From this perspective, teachers/coaches should didactically manipulate the factors that influence the acquisition of futsal-specific motor skills, such as goal setting, instruction and demonstration, feedback, and the organization, variation, and structure of practice [38]. Furthermore, knowing that older players are more effective defensively than younger ones allows teachers and coaches to understand the effect of chronological age on sports specialization. Thus, teachers and coaches should encourage players to leave their comfort zones and attain more consistent and diversified learning perspectives. Finally, this information is also pertinent to soccer because futsal is a typical developmental path for soccer players [6-9].

\section{Conclusions}

This study concluded, in relation to the technical actions numbers performed, that there were no significant differences between the categories in the number of technical actions, offensive technical actions, and defensive technical actions. But, players in the U-9 category executed more defensive technical actions on the defensive field than U-7 players did.

In relation to the successful technical actions, there were no significant differences between the categories in the number of offensive technical actions. However, U-9 and U-11 players executed more successful defensive technical actions that U-7 players. Moreover, players in the U-11 category also performed more successful defensive technical actions on the defensive field than U-7 players did.

No significant differences were observed between U-9 and U-11 players in relation to the ORs. There were no significant differences in the ORs in the technical actions or offensive technical actions. But, players in the U-9 and U-11 categories had approximately twoand three-fold higher odds, respectively, of executing successful defensive technical actions compared with players in the U-7 category.

Finally, according to the aggregated group analysis, players performed a higher number of offensive technical actions than defensive ones. They performed a higher number of successful offensive technical actions than defensive ones. Also, we reported a higher number of offensive technical actions on the offensive court half than of defensive technical actions on the defensive court half. Players performed a higher number of successful offensive technical actions on the offensive field than of defensive technical actions on the defensive field.

\section{Acknowledgements}

The authors thank the Estácio College of Sergipe for encouraging the research.

\section{Disclosure statement}

No author has any financial interest or received any financial benefit from this research.

\section{Conflict of interest}

The authors state no conflict of interest.

\section{References}

1. Guilherme J, Garganta J, Graça A, Seabra A. Influence of non-preferred foot technical training in reducing lower limbs functional asymmetry among young football players. J Sports Sci. 2015;33(17):1790-1798; doi: 10.1080/02640414.2015.1012100.

2. Corrêa UC, Alegre FAM, Freudenheim AM, dos Santos S, Tani G. The game of futsal as an adaptive process. Nonlinear Dynamics Psychol Life Sci. 2012;16(2):185204.

3. Costa IT, Garganta J, Greco PJ, Mesquita I, Maia J. System of tactical assessment in soccer (FUT-SAT): development and preliminary validation. Motri. 2011;7 (1):69-83; doi: 10.6063/motricidade.7(1).121.

4. Greco PJ. Tactical-technical knowledge: pendulum axis of tactical (creative) action in collective sports games [in Portuguese]. Rev Bras Educ Fís Esp. 2006; 20(Suppl. 5):210-212.

5. Garganta J. For a theory of team sports games [in Portuguese]. In: Graça A, Oliveira J (eds.), Teaching sports games [in Portuguese]. Porto: Centro de Estudos dos Jogos Desportivos; 1995; 11-25.

6. Travassos B, Araújo D, Davids K. Is futsal a donor sport for football?: exploiting complementarity for early diversification in talent development. Sci Med Football. 2018;2(1):66-70; doi: 10.1080/24733938.2017.1390322.

7. Müller E, Garganta J, Santos R, Teoldo I. Tactical behaviour and performance: comparative study between soccer and futsal players [in Portuguese]. R Bras Ci Mov. 2016;24(2):100-109.

8. Oppici L, Panchuk D, Serpiello FR, Farrow D. Futsal task constraints promote transfer of passing skill to soccer task constraints. Eur J Sport Sci. 2018;18(7):947954; doi: 10.1080/17461391.2018.1467490.

9. Oppici L, Panchuk D, Serpiello FR, Farrow D. Long-term practice with domain-specific task constraints influ- 
ences perceptual skills. Front Psychol. 2017;8:1387; doi: 10.3389/fpsyg.2017.01387.

10. Saad MA, Nascimento JV, Milisted M. Level of technical-tactical development in young futsal players considering the sporting experience [in Portuguese]. Rev Educ Fis UEM. 2013;24(4):535-544; doi: 10.4025/ reveducfis.v24.4.20333.

11. Ré A, Corrêa UC, Böhme MT. Anthropometric characteristics and motor skills in talent selection and development in indoor soccer. Percept Mot Skills. 2010; 110(3 Pt 1):916-930; doi: 10.2466/PMS.110.3.916-930.

12. Corrêa UC, de Pinho ST, da Silva SL, Clavijo FA, Souza TO, Tani G. Revealing the decision-making of dribbling in the sport of futsal. J Sports Sci. 2016;34(24): 2321-2328; doi: 10.1080/02640414.2016.1232488.

13. Travassos B, Bourbousson J, Esteves PT, Marcelino R, Pacheco M, Davids K. Adaptive behaviours of attacking futsal teams to opposition defensive formations. Hum Mov Sci. 2016;47:98-105; doi: 10.1016/j.humov.2016. 02.004 .

14. Schmidt R, Lee T. Learning and motor performance: from principles to application [in Portuguese]. Porto Alegre: Artmed; 2016.

15. Memmert D, Roth K. The effects of non-specific and specific concepts on tactical creativity in team ball sports. J Sports Sci. 2007;25(12):1423-1432; doi: 10.1080/ 02640410601129755.

16. Miloski B, Pinho JP, Freitas CG, Marcelino PR, Arruda AF. Which technical-tactical actions performed in futsal matches can discriminate the result of winning or defeat? [in Portuguese]. Rev Bras Educ Fís Esporte. 2014;28(2):203-209; doi: 10.1590/1807-55092 014000200203.

17. Coutinho D, Gonçalves B, Travassos B, Abade E, Wong DP, Sampaio J. Effects of pitch spatial references on players' positioning and physical performances during football small-sided games. J Sports Sci. 2019; 37(7):741-747; doi: 10.1080/02640414.2018.1523671.

18. Amaral R, Garganta J. Game modelling in futsal. Sequential analysis of $1 \mathrm{x} 1$ in attacking process [in Portuguese]. Rev Port Cien Desp. 2005;5(3):298-310; doi: 10.5628/rpcd.05.03.298.

19. Clemente FM, Figueiredo AJ, Martins FM, Mendes RS, Wong DP. Physical and technical performances are not associated with tactical prominence in U14 soccer matches. Res Sports Med. 2016;24(4):352-362; doi: 10.1080/15438627.2016.1222277.

20. Praça G, Soares VV, Matias CJA, da Costa IT, Greco PJ. Relationship between tactical and technical performance in youth soccer players. Rev Bras Cineantropom Desempenho Hum. 2015;17(2):136-144; doi: 10.5007/1980-0037.2015v17n2p136.

21. Serrano JM, Santos SD, Sampaio AJ, Leite NM. Sport initiation, early sport involvement and specialization in futsal training in Portugal [in Portuguese]. Motriz: Rev Educ Fis. 2013;19(1):99-113; doi: 10.1590/ S1980-65742013000100010.
22. Garganta J. Performance analysis in sports games. Review of game analysis [in Portuguese]. Rev Port Cien Desp. 2001;1(1):57-64; doi: 10.5628/rpcd.01.01.57.

23. Dancey C, Reidy J. Statistics without mathematics for psychology [in Portuguese]. Porto Alegre: Penso; 2013.

24. Espírito-Santo H , Daniel F. Calculating and reporting effect sizes on scientific papers (1): $p<0.05$ limitations in the analysis of mean differences of two groups [in Portuguese]. Rev Port Invest Comport Soc. 2015;1(1): 3-16; doi: 10.7342/ismt.rpics.2015.1.1.14.

25. Altman DG. Practical statistics for medical research. London: Chapman and Hall; 1991.

26. Robinson G, O’Donoghue P. A weighted kappa statistic for reliability testing in performance analysis of sport. Int J Perform Anal Sport. 2007;7(1):12-19; doi: 10.1080/ 24748668.2007.11868383.

27. Américo HB, Cardoso FS, Machado GF, Andrade MO, Resende ER, da Costa IT. Analysis of the tactical behavior of youth academy soccer players. J Phys Educ. 2016;27(1):1-9; doi: 10.4025/jphyseduc.v27i1.2710.

28. Reis MA, Vasconcellos FV, Almeida MB. Performance and tactical behavior of youth soccer players. Rev Bras Cineantropom Desempenho Hum. 2017;19(2):242-250; doi: 10.5007/1980-0037.2017v19n2p242.

29. Liu H, Gomez MÁ, Lago-Peñas C, Sampaio J. Match statistics related to winning in the group stage of 2014 BrazilFIFA World Cup.J Sports Sci.2015;33(12):12051213; doi: 10.1080/02640414.2015.1022578.

30. Castellano J, Casamichana D, Lago C. The use of match statistics that discriminate between successful and unsuccessful soccer teams. J Hum Kinet. 2012;31(1): 139-147; doi: 10.2478/v10078-012-0015-7.

31. Piaget J. Cognitive development in children: Piaget. Development and learning. J Res Sci Teach. 1964;2(3): 176-186; doi: 10.1002/tea.3660020306.

32. Matta MO, Figueiredo AJ, Garcia ES, Werneck FZ, Seabra A. Morphological and maturational predictors of technical performance in young soccer players. Motriz: Rev Educ Fis. 2014;20(3):280-285; doi: 10.1590/ S1980-65742014000300006.

33. Furley P, Memmert D. Coaches' implicit associations between size and giftedness: implications for the relative age effect. J Sports Sci. 2016;34(5):459-466; doi: 10.1080/02640414.2015.1061198.

34. Santos RM, Dias CM, Silva JM, da Costa IT. Does playing surface influence the tactical performance of soccer players? [in Portuguese]. RevEduc Fis UEM. 2013;24(2): 247-252; doi: 10.4025/reveducfis.v24.2.17965.

35. O'Connor D, Larkin P, Williams AM. What learning environments help improve decision-making? Phys Educ Sport Pedagogy. 2017;22(6):647-660; doi: 10.1080/ 17408989.2017.1294678.

36. Memmert D, Almond L, Bunker D, Butler J, Fasold F, Griffin L, et al. Top 10 research questions related to teaching games for understanding. Res Q Exerc Sport. 2015;86(4):347-359; doi:10.1080/02701367.2015.108 7294. 
37. Araújo D, Fonseca C, Davids K, Garganta J, Volossovitch A, Brandão $R$, et al. The role of ecological constraints on expertise development. Talent Dev Excel. 2010;2(2):165-179.

38. Corrêa UC, Pinho S, Silva Filho A. Motor learning and futsal teaching [in Portuguese]. In: Tani G, Corrêa UC (eds.), Motor learning and sport teaching [in Portuguese]. São Paulo: Blucher; 2016; 163-177. 